\title{
General Practitioners, Patients, and Care Givers Support the Use of a Telegeriatric Memory Disorder Consultation for Older Adults
}

\author{
Melinda Martin-Khan ${ }^{1,2 *}$, Salih A. Salih ${ }^{1,3}$, Jeffrey Rowland4, Richard Wootton ${ }^{5,6}$, \\ Leonard C. Gray 1,2 \\ ${ }^{1}$ Centre for Research in Geriatric Medicine, School of Medicine, University of Queensland, Princess Alexandra \\ Hospital, Woolloongabba, Australia \\ ${ }^{2}$ Centre for Online Health, University of Queensland, Royal Children's Hospital, Herston, Australia \\ ${ }^{3}$ Redlands Hospital, Queensland Health, Redlands, Australia \\ ${ }^{4}$ Prince Charles Hospital, Queensland Health, Chermside, Australia \\ ${ }^{5}$ Norwegian Centre for Integrated Care and Telemedicine, University Hospital of North Norway, Tromso, \\ Norway \\ ${ }^{6}$ Faculty of Health Sciences, University of Tromso, Tromso, Norway \\ Email: m.martinkhan@uq.edu.au
}

Received 10 January 2015; accepted 30 January 2015; published 5 February 2015

Copyright (C) 2015 by authors and Scientific Research Publishing Inc.

This work is licensed under the Creative Commons Attribution International License (CC BY).

http://creativecommons.org/licenses/by/4.0/

c) (i) Open Access

\section{Abstract}

Evidence has shown that diagnosis of dementia is reliable via video conference, but uptake of telehealth in this field has been slow. The aim of this paper was to consider the feasibility of implementing a telegeriatric memory disorder consultation as a standard clinical service and to assess stakeholder satisfaction with such a service. Method: The focus was on patient population located some distance from access to specialist services. General Practitioners (GPs) located in a remote area referred patients for a video consultation (VC) for cognitive assessment. A satisfaction survey was completed by referring GPs, patients or care givers, and the geriatrician. Results: Seven GPs agreed to participate in the pilot. Nine patients were referred for assessment, eight were diagnosed with dementia. GPs identified the specialist input as significant to patient care. Participants interacted with the specialist on a level that was comparable to a face-to-face assessment. Conclusion: It was clinically feasible to implement a telegeriatric memory disorder clinic. GPs, patients and their families living in a remote area found that a telegeriatric memory consultation was a highly satisfactory alternative to traveling to a major city for a memory assessment. Key Points: 1) GPs judged

"Corresponding author.

How to cite this paper: Martin-Khan, M., Salih, S.A., Rowland, J., Wootton, R. and Gray, L.C. (2015) General Practitioners, Patients, and Care Givers Support the Use of a Telegeriatric Memory Disorder Consultation for Older Adults. Advances in Alzheimer's Disease, 4, 1-9. http://dx.doi.org/10.4236/aad.2015.41001 
the diagnosis and recommendations by the specialist to be reliable and would recommend the service; 2) Rather than travel a long distance to see a specialist, attending the appointment via video conference is a suitable alternative for geriatric cognitive assessment.

\author{
Keywords
}

Aged, 80 and over, Cognition, Telemedicine

\title{
1. Introduction
}

Dementia is a common condition in older people around the world. In Australia, it is the fourth most common cause of death for Australians living outside a major city [1]. The slow onset of dementia makes detecting the transition between normal aging and the onset of dementia challenging [2]. Research has shown that General Practitioners (GPs) often miss the initial signs of cognitive impairment and that there are lengthy delays to diagnosis. If diagnosis does occur, differential diagnosis is challenging given the clinical overlap in presentation of the most common dementia types [3]. In some instances, the GP will refer to a specialist because of the challenges associated with diagnosis and management of dementia; if a referral is made, rural patients are usually required to travel long distances to attend a memory disorder clinic.

A memory assessment can be an anxious experience, compounded by the need to travel (often a difficult experience for older patients) [4]-[6]. This can negatively impact on the performance of patients [5]. Poor performance may have repercussions in relation to diagnosis and treatment. A video conference consultation (VC) is a reliable alternative and can eliminate some of the unnecessary anxiety caused by travel and the necessity of adapting to an unfamiliar environment for the assessment process [7]-[13]. The success of such a service relies heavily on the acceptance of referring GPs, patients and their care givers [14], and the economic viability of such a service [15]. Despite the evidence, the uptake of telehealth memory clinic services has been slow. The translation of research evidence into practice (knowledge translation) is an important next step into change management.

The Centre for Research in Geriatric Medicine at the University of Queensland, based at the Princess Alexandra Hospital (PAH), Brisbane, conducted a small pilot project to test the feasibility of a memory disorder service to provide cognitive assessments for older adults via VC. The service linked a geriatrician based in Brisbane with patients living in the Mount Isa Health Service District. Mount Isa City is a large rural city in Queensland, Australia, covering an area of over 43,000 square kilometres $\left(\mathrm{km}^{2}\right)$. With a population of 23,000 , Mount Isa is located $1800 \mathrm{~km}$ from Brisbane.

This study examined user satisfaction with a telegeriatric memory disorder consultation.

\section{Methods}

A telegeriatric memory disorder clinic was established at Mt. Isa and surveys were used to assess user satisfaction. Weekly video conferencing consultations were held with a telehealth model which included medical history taking and assessment completed by staff at the local site in-person, and specialist consultation by video at the remote site.

\subsection{Telegeriatric Memory Disorder Consultation}

\subsubsection{Patient Appointment}

All appointments required a referral to the memory disorder service by their GP. Attendance was managed by the local Aged Care Assessment Team. Referrals were generally initiated by the Aged Care Assessment Team following a community aged care assessment. The telegeriatric memory disorder consultation needs a host at the local site to coordinate the appointments for the patients, prepare the medical history, and to ensure that the room is available. This was managed by the Mount Isa Health Service District Aged Care Assessment Team.

An occupational therapist administered a series of assessments to the patient in a face to face interview. These included: Mini-Mental State Examination [16]; Informant Questionaire for Cognitive Decline in the Elderly [17]; 
and the Rowland Universal Dementia Assessment Scale [18]; along with a detailed history. A standard battery of clinical investigations was performed prior to attendance at the clinic, including laboratory tests and a CT brain scan. This information was transferred by facsimile to the specialist located in Brisbane prior to the VC.

\subsubsection{Equipment}

Local VC equipment was located at five different sites in the Mount Isa Health Service District. These were Cloncurry, Karumba, Mount Isa, Normanton and Richmond. These towns are located between 1710 and 2160 $\mathrm{km}$ from Brisbane (Figure 1). Available bandwidth varied between sites, ranging from $128 \mathrm{kbs}$ to $384 \mathrm{kbs}$. VC connections were predominantly Internet Protocol (IP) at $128 \mathrm{kbs}$.

A conference room equipped with $\mathrm{VC}$ equipment was used at the $\mathrm{PAH}$ by the specialist geriatrician for the remote VC access. A Polycom Viewstation 128 video conferencing with a $51 \mathrm{~cm}$ Panasonic television screen was utilised at the PAH.

\subsubsection{Consultation}

A staff member was present with the patient and carer during the interview at the local site. The geriatrician (at the remote hospital site) interviewed the patient, the carer and staff member via VC. The following routine was common:

- Generally, the geriatrician met with the staff member first and discussed the medical information and clarified any missing or confusing details;

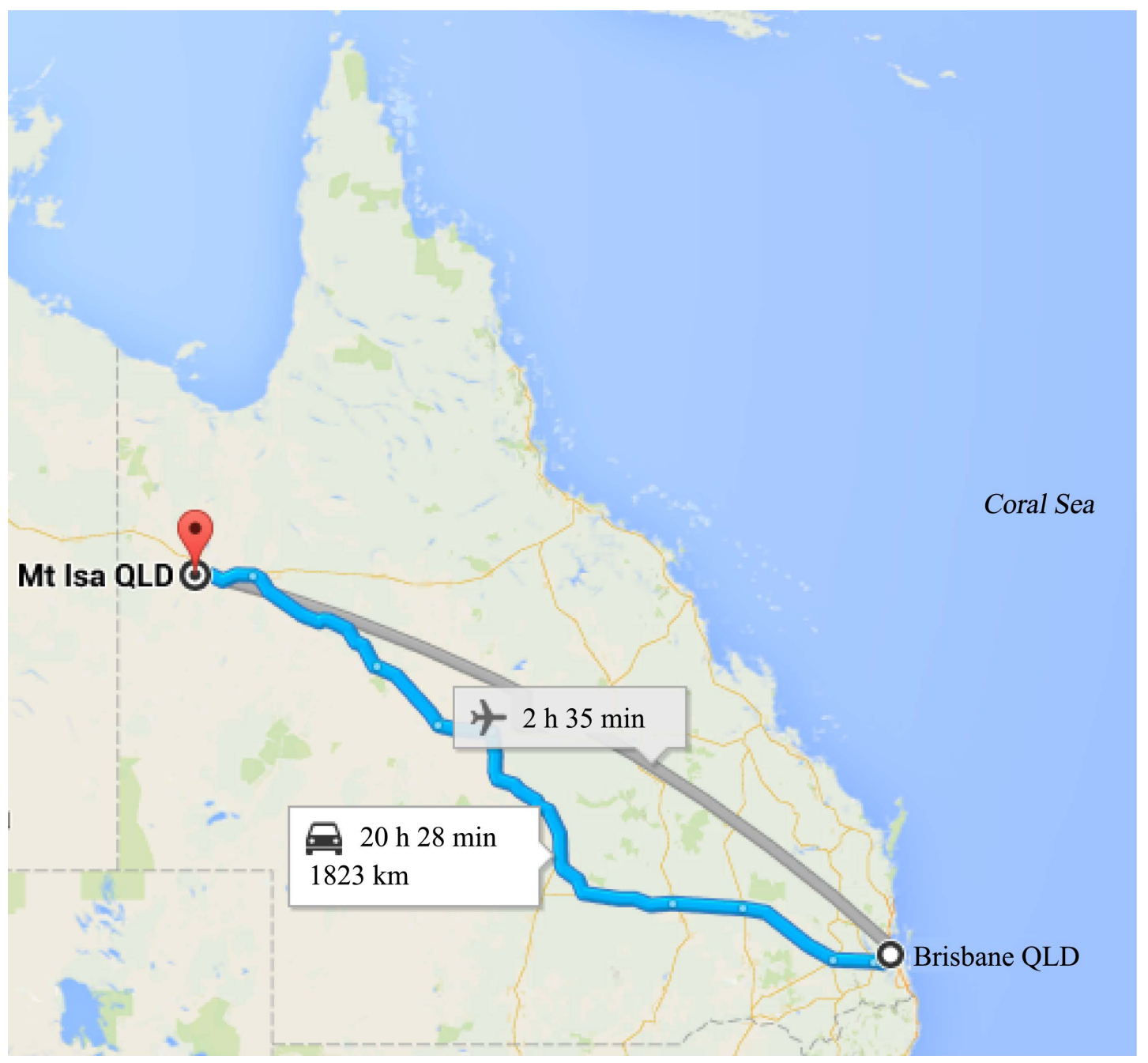

Figure 1. Distance from brisbane to Mt. Isa (Queensland, Australia) (google maps). 
- The doctor then met with the patient and the carer. The staff member was in attendance if the patient and family were comfortable;

- Depending on the situation the Geriatrician would sometimes meet with the carer individually while the staff member took the patient out of the clinic room (for refreshments or a short break). If appropriate the geriatrician discussed the diagnosis and recommendations with the patient and carer;

- The process began again if there was a second consultation for that day;

- Finally, the Geriatrician met with the staff member and summarised the outcome of the sessions, indicating what would be sent to the GP for each patient, and the local staff member would give the Geriatrician information regarding the consultations for the next week.

A formal letter was prepared by the specialist for the referring GP including any diagnosis and/or recommendations which the GP might take into consideration when finalising the treatment plan.

\subsection{Satisfaction Surveys}

Satisfaction surveys were distributed to all eligible participants. The sample comprised stakeholders involved in the pilot telegeriatric memory disorder clinic operating for four months. Ethics approval for this study was obtained from the Townsville Health Service District Human Research Ethics Committee. Participation in the survey constituted evidence of consent.

GPs were surveyed (in person, by the Aged Care Assessment Team staff) several weeks after patients had returned to their surgery for review. They were asked to complete a survey for each patient they had referred, and to reflect on the impact the VC consultation had on the clinical management of the care for the patient.

The Post-Interview Survey for patients or care givers was a Quality Assurance survey written by the Mt Isa Aged Care Assessment Team to assist in their local evaluation of the telegeriatrics clinic. It was administered immediately following each VC.

The Follow-up Carer Survey [10] [14] [19] was an anonymous survey posted to the carer after willingness to participate was established by phone. This survey allowed the carer to reflect on the impact of the video consultation for patient care some months after the $\mathrm{VC}$ had occurred.

The specialist survey [10] [14] [19] was a once only survey completed directly after the last VC in the study period.

\section{Results}

The staff at the Mt Isa Aged Care Assessment Team had no previous experience with telemedicine. Nine patients from the Mount Isa region were identified for geriatrician consultation based on concerns regarding their cognitive function; all agreed to participate in the trial. The average duration of the VC consultation was 45 minutes (range 30 - 60 minutes; SD 12.5). The average age of patients was 78 years (SD 4.5, 71 - 85). Two were male. The mean Mini-Mental State Examination was 19 (SD 5.87, 7 - 28). Eight patients were diagnosed with dementia: Alzheimer's disease $(n=4)$; vascular disease $(n=2)$; Alzheimer's disease/vascular disease $(n=2)$; Cognitive impairment not meeting full criteria for dementia $(n=1)$. Nine medication recommendations were made. No patient was referred for a physical examination or additional review at the Memory Disorder Service in the city.

\subsection{Satisfaction Surveys}

\subsubsection{Referring GP Evaluation}

Seven local GPs were involved in referring patients to the telegeriatric memory disorder clinic, three of whom had prior experience with a telehealth service. All agreed to participate in the survey.

The survey asked two questions which focused on the relevance of the video conference to the clinical decision making process of the GP: firstly, a question of reliability which was defined as the extent to which the GP trusted the information provided by the specialist (i.e. was the GP willing to use the information when making a clinical decision for the patient); and secondly, a question regarding the contribution of the specialist assessment to patient care (i.e. did the GP use the information when making a clinical decision for the patient). We would expect internal consistency between these two answers if the service was well received - that the GP was both willing to trust the information from the specialist and that the information was useful when making a clinical 
decision. Each GP indicated that they felt the diagnosis and information supplied by the geriatrician was reliable and that the provision of the telegeriatric memory disorder consultation made a significant contribution to their patient care.

The GPs indicated, due to the distance involved, that travel to another location for assessment would not have been feasible for five of the patients. They stipulated that for these five patients, they would not have made the referral because the challenges associated with travel, would have outweighed the perceived benefits of the consultation. Having seen the benefit of the consultation for each of these patients, and having had the challenges of the travel removed, they can see that the consultation was to the patient's advantage. All GPs would recommend this telehealth service to other medical practitioners (Table 1).

\subsubsection{Patient/Carer Evaluation}

Two patients and five care givers completed questionnaires. At three interviews, patient/carer satisfaction was not evaluated. Of these three interviews, two patients were of Non-English Speaking Background (NESB), one of whom attended alone (family provided carer information at a different time). These were the only NESB patients involved in the study. The third patient attended with a paid carer. In relation to gender, age, RUDAS score, diagnosis or relationship to carer, there were no identifiable differences between consenting and nonconsenting parties. For all three non-participating patients the GP reported satisfaction with the service.

Participating patients and care givers $(n=7)$ were satisfied with the videoconferencing process. Their experience of the VC matched the explanations they had received in advance. On the day, they felt that the sound and vision of the $\mathrm{VC}$ were of good quality and they could communicate easily with the geriatrician. The level of privacy during the $\mathrm{VC}$ was acceptable to all but one participant who would have preferred to talk to the geriatrician via $\mathrm{VC}$ with no one else in the room.

Care givers and patients responded positively to the specialist assessment process (duration and procedures). Given two format options for attending an assessment in the same location (either a video conference with a geriatrician, or a geriatrician present for a face-to-face assessment), only one person said they preferred the faceto-face assessment. One patient preferred the VC because they liked the format. Given the option of a VC or the patient having to travel to see the geriatrician face-to-face, every participant identified the $\mathrm{VC}$ as the preferred option. All care givers indicated they would request a $\mathrm{VC}$ if a repeat consultation was required based on issues relating to travel or the health of the patient or carer.

Care givers indicated that a trip to Townsville, located $900 \mathrm{~km}$ from Mt. Isa, for a one hour interview with a specialist would take two to three days, involving overnight accommodation and several flights. Three care givers indicated that they would need to take time off work to attend, and that they would have out-of-pocket expenses of up to AU $\$ 1000$. Other care givers were retired and didn't need to factor in work commitments.

Table 1. General practitioner satisfaction survey regarding a patient consultation via video conference for cognitive assessment.

\begin{tabular}{|c|c|c|}
\hline GP responses about the service $(n=7)$ & Yes & No \\
\hline Have you any experience with a telehealth service previously? & 3 & 4 \\
\hline $\begin{array}{l}\text { Did you feel that the diagnosis and information } \\
\text { supplied to you by the geriatrician was reliable? }\end{array}$ & 7 & \\
\hline $\begin{array}{l}\text { Do you think the telegeriatric service reduced the waiting time } \\
\text { for your patient to access specialist assessment? }\end{array}$ & 7 & \\
\hline Would you recommend the telegeriatric service to other doctors? & 7 & \\
\hline GP responses about individual patient consultations $(n=9)$ & Yes & No \\
\hline \multirow[t]{2}{*}{$\begin{array}{l}\text { If the video conference consultation was not available, would it have } \\
\text { been feasible to arrange a similar assessment through other methods? }\end{array}$} & 4 & 5 \\
\hline & Very Significant & Significant \\
\hline $\begin{array}{l}\text { How significant was the contribution of the telegeriatric } \\
\text { service to your patient care? (5 level Liket scale) }\end{array}$ & 7 & 2 \\
\hline
\end{tabular}




\subsubsection{Specialist Evaluation}

In the survey administered following the last $\mathrm{VC}$ assessment, the specialist identified himself as a novice (no use of VC previously) who found the VC equipment surprisingly user friendly. In response to the question "Did you think you would be able to identify a differential diagnosis or a treatment plan" (two separate questions), the specialists indicated yes on both counts. For the survey question "How confident are you with the clinical assessments you have made", the specialist response was "very confident".

\section{Discussion}

A telegeriatric memory disorder consultation is only feasible if the GPs in the area have confidence in the assessment process and are willing to refer patients to the service. In this study, the GPs were faced with the very real prospect of having to choose whether to send their patient on a long journey for the consultation, so they were balancing the diagnostic gains against the challenge of travel. If, as many studies have suggested, GPs tend to identify cognitive impairment when it is more advanced, then the patient would be even less likely to be able to travel. In this study, the GPs all indicated that as the service was local it made a useful contribution to the care of the patient, and that they were willing to refer additional patients. It should be noted that all the patients had relatively straightforward diagnoses and the presence of unusual causes of dementia or complex behavioural symptoms associated with the dementing process, could affect the efficacy and satisfaction of this type of longdistance evaluation. It will either challenge the telehealth modality or the additional support, where none was previously experience, may enhance the satisfaction of local clinicians.

Given that the consultation occurs via VC, there is limited opportunity for physical examination. A purposeful response to this limitation needs to be taken. It's important that GPs understand the limitations of a VC and that they consider the recommendations of the specialist in light of the interview format. While the geriatrician can watch the patient walk into the clinic room and can move the VC camera to do some closer skin inspections, there is no physical examination by the geriatrician in the traditional sense. If a physical examination is required, the geriatrician may ask the staff member in attendance to carry out a specific task if they have the required training (medical registrar, registered nurse); they may put a request in the letter to the GP for a follow up physical examination if required; or the patient may be asked to attend a consultation in the city at the primary memory clinic. Generally, a physical examination is not required for the diagnosis of dementia, but may be used for differential diagnosis of less common forms of dementia. A physical examination wasn't required for the diagnosis of any patients in this study, but for more complex cases, a referral to the city for additional assessment may be required. In addition, the physical examination may provide other helpful information during a standard consultation, such as the identification of another issue unconnected to the dementia, which would not be evident during a VC. This is uncommon [20]. While a referral to the city would be unfortunate, it is important to remember that the majority of patients would have been diagnosed at the initial consultation, and only the more complex patients would be asked to travel for an additional diagnostic workup. In this way, the telegeriatric memory consultation has significantly reduced the amount of travel, even if it is not completely eliminated.

The service model was developed to ensure that the carer or patient was not left alone in the room during a VC link with the specialist, due to the assumption that the patient may be uncomfortable. This raised questions regarding patient privacy and the additional interaction that occurred as a result of the telemedicine consultation. One patient indicated in the survey response that they would have preferred to speak with the specialist via the video conference without other staff in the room. The service model should be modified to accommodate patient preferences. The interaction with the specialist was highly acceptable to care givers and patients, such that support staff being in the room to facilitate carer interaction with the specialist would not always be required, once the consultation had commenced.

The need to avoid travelling long distances is a high priority for patients and their care givers. The reasons may vary. For some care givers, travelling requires time off work and the need to make arrangements for their immediate family to be taken care of while they are away. As the patients are elderly and some of the care givers are spouses, the long distance travel can be difficult for health reasons. This means that often they take longer to make the journey in order to manage it more successfully. Care givers (and patients) worry about doing well in the assessment process and they perceive a long journey as a significant factor in their performance. In some instances, the patient's GP indicated that no assessment would have occurred if the VC had not been available as it wasn't feasible for the patient to travel. 
For patients and care givers involved in the evaluation of this telegeriatric memory disorder consultation, VC is seen as a highly favourable alternative because they perceive the result of the $\mathrm{VC}$ assessment as reliable, they feel that they have experienced a meaningful interaction with the specialist and they have managed to avoid a stressful journey.

Unlike a standard outpatient clinic, where a patient is referred and arrives at the specialist's clinic where the staff manage the appointment in the specialist's office, a telemedicine appointment involves duplication of the workforce. To enable this service to operate, appointments need to be managed at the clinic for the local site and the remote site. Staff need to be present to host the patient at the local site, and to (more or less) host the specialist at the distant site. This poses challenges for the implementation of telehealth. In this pilot, the Aged Care Assessment Team identified the need for geriatrician support and so incorporated the clinic into their service, but this is not always the case. Apart from the workforce, and the building cost, there is also the need for video conferencing equipment (a set at the local and remote site). Economic studies have shown that when a certain number of patients need to be seen, or the distance is extreme, regardless of the need for extra staff and extra equipment, it is cost effective to have a telehealth service [15]. Efficiencies established by maximising the equipment use improve the business case for telegeriatric memory disorder clinics. For example, in Queensland, where this study was carried out, VC equipment is standard in hospitals and community clinics. Therefore, the cost of implementation is reduced because the equipment is already in place, and the implementation of this service is improving the utilisation of an existing resource.

The model implemented in this pilot involved training staff at one site to administer a suite of cognitive assessment tools and to take a medical history (in person) in the style that provided a geriatrician with the information needed to carry out a memory assessment (via VC). This is feasible when the model is based on a formal telegeriatric clinic operational from one location on a regular basis. If the model is a statewide referral system, utilising a broad network of VC equipment, without the consistency of regular staff (but rather the acceptance of ad-hoc referrals) issues of reliability of the cognitive assessments and information collected may arise. Work has been done to consider the reliability of administering cognitive assessment tools using video conferencing (administering and scoring via VC rather than in-person) [21]-[26]. This is feasible if required. The model of inperson assessment is more efficient if you have the luxury of a regular clinic (as it reduces the time pressure on the specialist), but if necessary, the specialist can administer the cognitive assessment tools via VC.

There are a growing number of publications supporting the use of video conferencing for the diagnosis and management of dementia. One such paper [27] published in 2000 describes a Dementia Telehealth Center in Korea which provided services between a larger university hospital and a nearby nursing home and welfare centre (approximately $35 \mathrm{~km}$ from the hospital). The primary focus was care and management of people with dementia, along with diagnosis services for people who had already declined to the point that they were using community day centres or residential care. While the Lee paper highlights the value a telehealth service provides for a frail urban population (the recipients lived only $35 \mathrm{~km}$ from the university hospital, all users of a day care center or residents of a nursing home), this current paper describes a different population on two counts: It is both less urban (being $1800 \mathrm{~km}$ from the University hospital in Brisbane from which the telehealth service operated), and less frail. The participants were all community dwelling individuals, many were living alone and were recommended for review by their GP and the local Aged Care Assessment Team. While the two papers highlight the challenges that telehealth can overcome, it was interesting to note in the Lee paper some of the participants travelled the $35 \mathrm{~km}$ to undergo laboratory or neuroimaging tests or detailed neurologic examinations for the diagnostic work-up of dementia. Only $7 \%$ of the registered patients $(n=4)$ received continuous follow-up using the telehealth system. This is a common telehealth model where some standard face-to-face consultations are substituted for telehealth consultations. Given the model described in this paper, the longer distances for travel make the decision for additional testing a more significant one; as travel is a greater burden. In all nine cases, the telehealth system was used to complete the full diagnostic service and no patient was required to travel to the city.

\section{Conclusion}

Unlike many studies, this pilot was carried out in a telehealth population (a group of patients where the service was genuinely required). Without this telegeriatric clinic, the majority of these patients would not have had the opportunity to see a geriatrician. All but one patient was diagnosed with dementia. This pilot service provided an 
opportunity for patients, their care givers, and the local clinical team, to see a specialist without having to travel. This was valued and appreciated. The clinical utility was shown for local practitioners and specialists. The pilot was an opportunity to consider the translation of research evidence into practice.

\section{Acknowledgements}

We acknowledge the work of Kerrie Lord and Jennifer Handyside for clinical support during this project.

\section{Key Points}

- Rural patients can access specialist assessment for memory problems by participating in a telegeriatric memory disorder consultation that links the remote specialist to the patient via video conference;

- GPs found the telegeriatric memory disorder consultation was a reliable and significant support for patient care;

- Video consultation for cognitive assessment is preferred by patients and care givers as an alternative to a live consultation when $>1000 \mathrm{~km}$ travel is required.

\section{References}

[1] Australian Bureau of Statistics (2013) 3218.0-Regional Population Growth, Australia, 2011-12. http://www.abs.gov.au/ausstats/abs@.nsf/Products/3218.0 2011-12 Main+Features Main+Features?OpenDocument

[2] Seeher, K., Withall, A. and Brodaty, H. (2011) The Dementia Research Mapping Project. The 2010 Update Final Report, Dementia Collaborative Research Centre, Assessment and Better Care, Sydney.

[3] Braaten, A.J., et al. (2006) Neurocognitive Differential Diagnosis of Dementing Diseases: Alzheimer's Dementia, Vascular Dementia, Frontotemporal Dementia, and Major Depressive Disorder. The International Journal of Neuroscience, 116, 1271-1293. http://dx.doi.org/10.1080/00207450600920928

[4] Aquilina, C. and Matthews, D. (2006) Cognitive Impairment Precipitated by Air Travel. International Journal of Geriatric Psychiatry, 21, 398-399. http://dx.doi.org/10.1002/gps.1498

[5] Webster, J. and Grossberg, G.T. (2003) Chapter 5 Differential Diagnosis of Agitation in Dementia: Delirium, Depression, Psychosis, and Anxiety. In: Hay, D.P., et al., Eds., Agitation in Patients with Dementia: A Practical Guide to Diagnosis and Management, American Psychiatric Publishing, Inc., Washington DC, 67-79.

[6] Johnston, D. and Jones 3rd, B.N. (2001) Telepsychiatry Consultations to a Rural Nursing Facility: A 2-Year Experience. Journal of Geriatric Psychiatry \& Neurology, 14, 72-75. http://dx.doi.org/10.1177/089198870101400205

[7] Loh, P.K., et al. (2004) Can Patients with Dementia Be Assessed at a Distance? The Use of Telehealth and Standardised Assessments. Internal Medicine Journal, 34, 239-242. http://dx.doi.org/10.1111/j.1444-0903.2004.00531.x

[8] Loh, P.-K., et al. (2007) Development of a Telemedicine Protocol for the Diagnosis of Alzheimer's Disease. Journal of Telemedicine and Telecare, 13, 90-94. http://dx.doi.org/10.1258/135763307780096159

[9] Loh, P.K., et al. (2005) Diagnostic Accuracy of Telehealth Community Dementia Assessments. Journal of the American Geriatrics Society, 53, 2043-2044. http://dx.doi.org/10.1111/j.1532-5415.2005.00479 8.x

[10] Saligari, J., et al. (2002) The Clinical Achievements of a Geriatric Telehealth Project in Its First Year. Journal of Telemedicine and Telecare, 8, 53-55.

[11] Martin-Khan, M., Varghese, P., Wootton, R. and Gray, L. (2007) Successes and Failures in Assessing Cognitive Function in Older Adults Using Video Consultation. Journal of Telemedicine and Telecare, 13, 60-62. http://dx.doi.org/10.1258/135763307783247211

[12] Shores, M.M., Ryan-Dykes, P., Williams, R.M., Mamerto, B., Sadak, T., Pascualy, M., et al. (2004) Identifying Undiagnosed Dementia in Residential Care Veterans: Comparing Telemedicine to In-Person Clinical Examination. International Journal of Geriatric Psychiatry, 19, 101-108. http://dx.doi.org/10.1002/gps.1029

[13] Martin-Khan, M., Flicker, L., Wootton, R., Loh, P.K., Edwards, H., Varghese, P., et al. (2012) The Diagnostic Accuracy of Telegeriatrics for the Diagnosis of Dementia via Video Conferencing. Journal of the American Medical Directors Association, 13, 487.e19-487.e24.

[14] Smith, A., Isles, A., McCrossin, R., Van der Westhuyzen, J., Williams, M., Woollett, H. and Wootton, R. (2001) The Point of Referral Barrier-A Factor in the Success of Telehealth. Journal of Telemedicine and Telecare, 7, 75-78. http://dx.doi.org/10.1258/1357633011937227

[15] Comans, T.A., Martin-Khan, M., Gray, L.C. and Scuffham, P.A. (2013) A Break-Even Analysis of Delivering a Memory Clinic by Videoconferencing. Journal of Telemedicine and Telecare, 19, 393-396. 
http://dx.doi.org/10.1177/1357633X13506532

[16] Folstein, M., Folstein, S. and McHugh, P. (1975) Mini-Mental State: A Practical Method for Grading the Cognitive State of Patients for the Clinician. Journal of Psychiatric Research, 12, 189-198. http://dx.doi.org/10.1016/0022-3956(75)90026-6

[17] Cochrane, M., Cochrane, A., Jauhar, P. and Ashton, E. (2005) Acetylcholinesterase Inhibitors for the Treatment of Wernicke-Korsakoff Syndrome-Three Further Cases Show Response to Donepezil. Alcohol and Alcoholism, 40, 151154. http://dx.doi.org/10.1093/alcalc/agh127

[18] Iype, T., Ajitha, B.K., Antony, P., Ajeeth, N.B., Job, S. and Shaji, K.S. (2006) Usefulness of the Rowland Universal Dementia Assessment Scale in South India. Journal of Neurology, Neurosurgery \& Psychiatry, 77, 513-514. http://dx.doi.org/10.1136/jnnp.2005.069005

[19] Smith, A., Youngberry, K., Christie, F., Isles, A., McCrossin, R., Williams, M., et al. (2003) The Family Costs of Attending Hospital Outpatient Appointments via Videoconference and in Person. Journal of Telemedicine and Telecare, 9, 58-61. http://dx.doi.org/10.1258/135763303322596282

[20] Martin-Khan, M., Varghese, P., Wootton, R. and Gray, L. (2008) Physical Examination and Diagnosis of Dementia for Video Consultation. Journal of the American Geriatrics Society, 56, 947-949. http://dx.doi.org/10.1111/j.1532-5415.2008.01658.x

[21] Wong, L., Martin-Khan, M., Rowland, J., Varghese, P. and Gray, L.C. (2011) Reliability of the Rowland Universal Dementia Assessment Scale (RUDAS) via Video Conferencing. International Journal of Geriatric Psychiatry, 26, 988-989. http://dx.doi.org/10.1002/gps.2658

[22] Wong, L., Martin-Khan, M., Rowland, J., Varghese, P. and Gray, L.C. (2012) The Rowland Universal Dementia Assessment Scale (RUDAS) as a Reliable Screening Tool for Dementia When Administered via Videoconferencing in Elderly Post-Acute Hospital Patients. Journal of Telemedicine and Telecare, 18, 176-179. http://dx.doi.org/10.1258/jtt.2012.SFT113

[23] Saligari, J., Flicker, L., Loh, P.K., Maher, S., Ramesh, P. and Goldswain, P. (2002) The Clinical Achievements of a Geriatric Telehealth Project in Its First Year. Journal of Telemedicine and Telecare, 8, 53-55.

[24] Cullum, C.M., Weiner, M.F., Gehrmann, H.R. and Hynan, L.S. (2006) Feasibility of Telecognitive Assessment in Dementia. Assessment, 13, 385-390. http://dx.doi.org/10.1177/1073191106289065

[25] Grob, P., Weintraub, D., Sayles, D., Raskin, A. and Ruskin, P. (2001) Psychiatric Assessment of a Nursing Home Population Using Audiovisual Telecommunication. Journal of Geriatric Psychiatry and Neurology, 14, 63-65. http://dx.doi.org/10.1177/089198870101400203

[26] Ball, C. and McLaren, P. (1997) The Tele-Assessment of Cognitive State: A Review. Journal of Telemedicine and Telecare, 3, 126-131. http://dx.doi.org/10.1258/1357633971931020

[27] Lee, J.H., Kim, J.H., Jhoo, J.H., Lee, K.U., Kim, K.W., Lee, D.Y. and Woo, J.I. (2000) A Telemedicine System as a Care Modality for Dementia Patients in Korea. Alzheimer Disease and Associated Disorders, 14, 94-101. http://dx.doi.org/10.1097/00002093-200004000-00007 
Scientific Research Publishing (SCIRP) is one of the largest Open Access journal publishers. It is currently publishing more than 200 open access, online, peer-reviewed journals covering a wide range of academic disciplines. SCIRP serves the worldwide academic communities and contributes to the progress and application of science with its publication.

Other selected journals from SCIRP are listed as below. Submit your manuscript to us via either submit@scirp.org or Online Submission Portal.
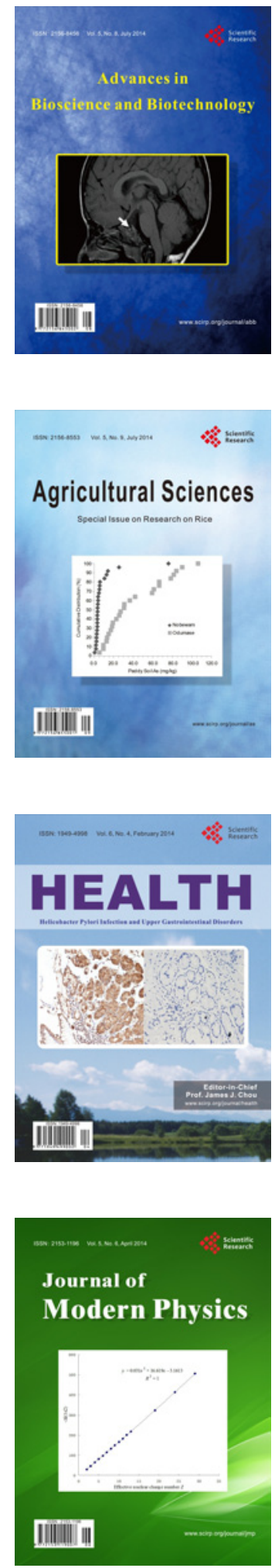
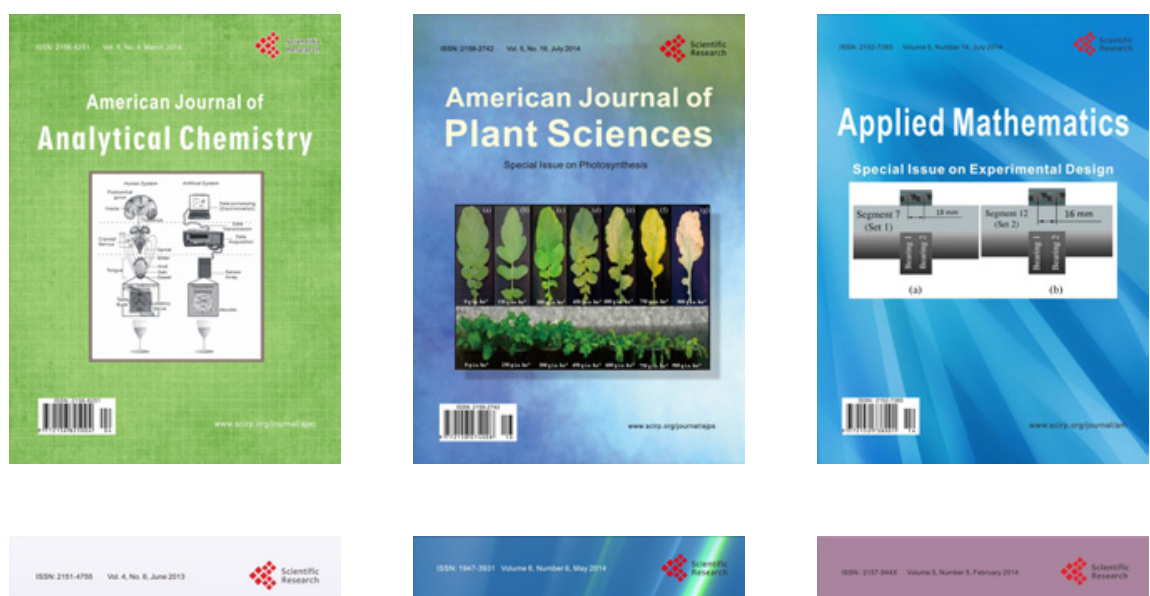

Creative Education
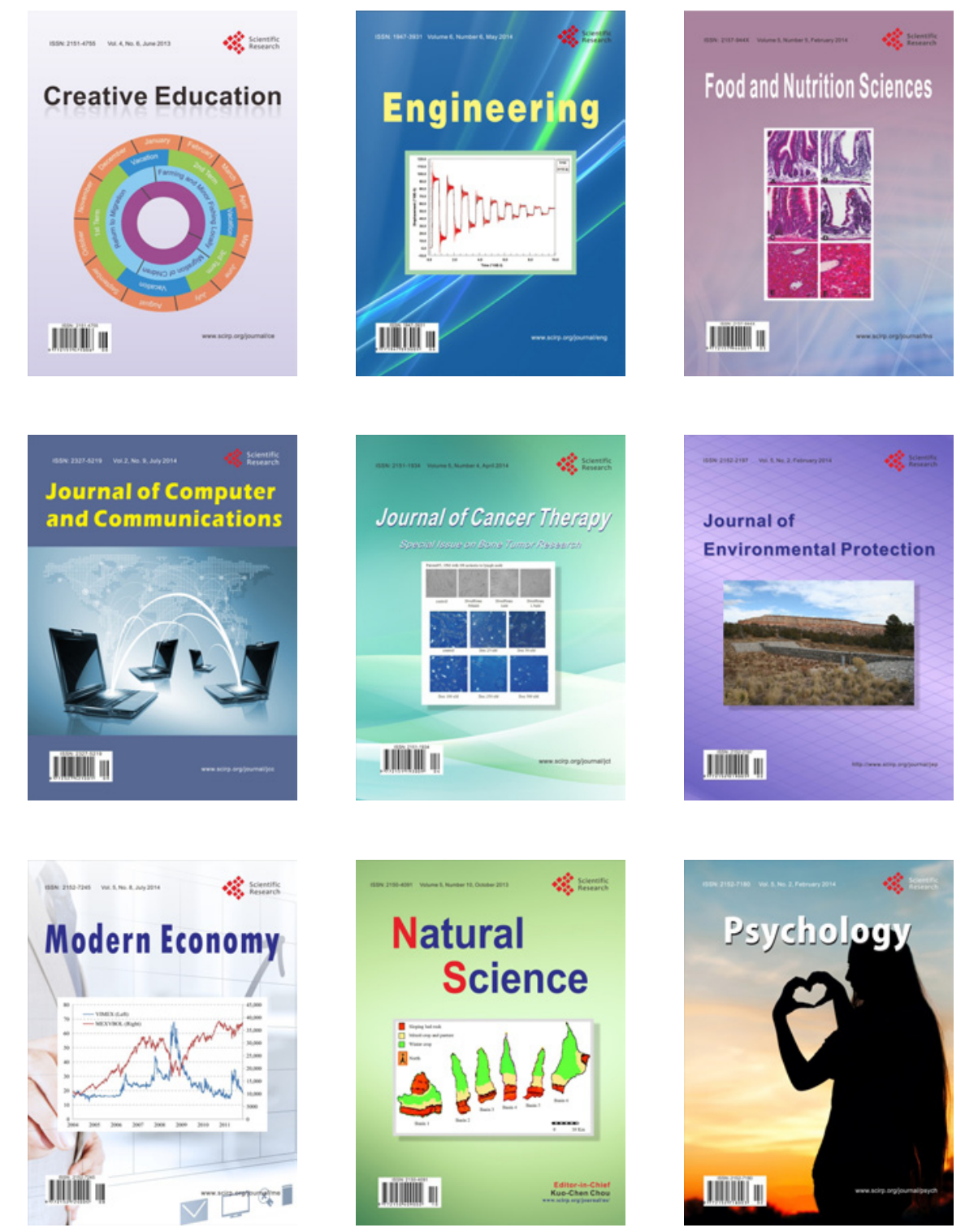